\title{
A Review on Communication Issues Related to The Process and Treatment for Breast Cancer Patients in Malaysia
}

Saidatun Najmiah Mohd Jamil, Jusang Bolong, Mohd Nizam Osman \& Tham Jen Sern

To Link this Article: http://dx.doi.org/10.6007/IJARBSS/v11-i12/11824

DOI:10.6007/IJARBSS/v11-i12/11824

Received: 20 October 2021, Revised: 23 November 2021, Accepted: 10 December 2021

Published Online: 16 December 2021

In-Text Citation: (Jamil et al., 2021)

To Cite this Article: Jamil, S. N. M., Bolong, J., Osman, M. N., \& Sern, T. J. (2021). A Review on Communication Issues Related to The Process and Treatment for Breast Cancer Patients in Malaysia. International Journal of Academic Research in Business and Social Sciences, 11(12), 858-867.

Copyright: (c) 2021 The Author(s)

Published by Human Resource Management Academic Research Society (www.hrmars.com)

This article is published under the Creative Commons Attribution (CC BY 4.0) license. Anyone may reproduce, distribute, translate and create derivative works of this article (for both commercial and non0-commercial purposes), subject to full attribution to the original publication and authors. The full terms of this license may be seen at: http://creativecommons.org/licences/by/4.0/legalcode

Vol. 11, No. 12, 2021, Pg. 858 - 867

Full Terms \& Conditions of access and use can be found at http://hrmars.com/index.php/pages/detail/publication-ethics 


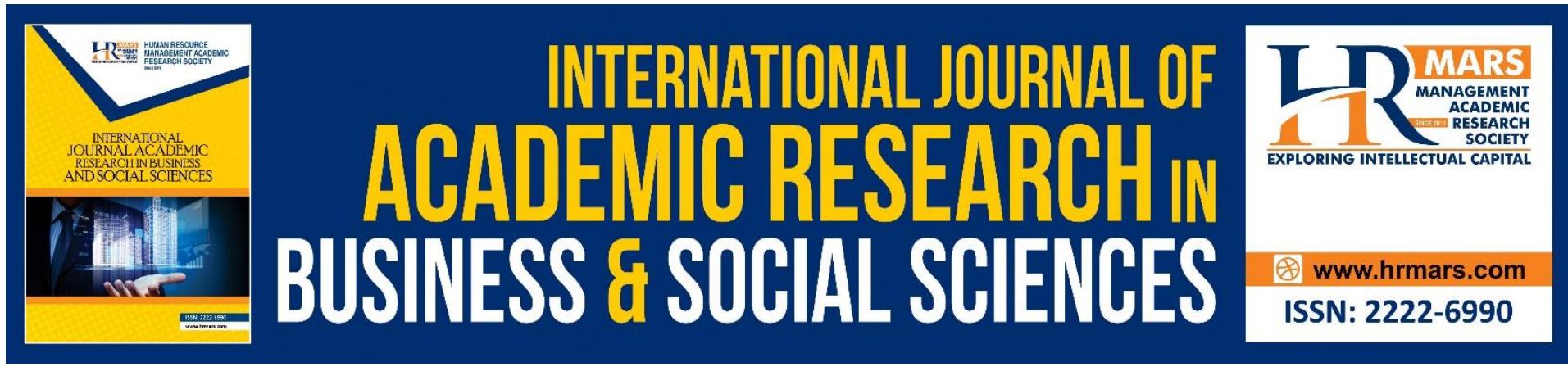

\title{
A Review on Communication Issues Related to The Process and Treatment for Breast Cancer Patients in Malaysia
}

\author{
Saidatun Najmiah Mohd Jamil, Jusang Bolong, Mohd Nizam \\ Osman \& Tham Jen Sern \\ Communication Department, Faculty of Modern Languages and Communication, \\ Universiti Putra Malaysia, Malaysia, Serdang
}

\begin{abstract}
Apart from the assistance from medical technology, the process and treatment for breast cancer patients are also closely related to the information perceived by the patients themselves. By stating this, consideration towards communication issues should then be taken into account. This article focuses on the most notable issue discussed in Malaysia in which the communication between breast cancer patients with family members, particularly the communication with the patient's partner effects the process and the treatment that they receive. The study in this article is needed to address the communication issues thus finding solutions which will help to reduce the stigma of breast cancer in Malaysia.

Keywords: Communication Issues, Breast Cancer Patients, Breast Cancer Treatment, Breast Cancer and Couples
\end{abstract}

\section{Introduction}

Breast cancer patients in Malaysia require assistance to overcome depression, emotional stress and other challenges while suffering. The presence of people who are closest to them particularly their own partner is crucial to help overcome the problems they face. This is due to the fact that the patient's partner would understand their condition better resulting to having lived together.

Yeoh, et al (2018) reported that breast cancer patients in Malaysia are among the patients with the lowest life expectancy in Asia Pacific that is only $49 \%$ of patients who have a chance to live for five years and $43 \%$ of patients at stage three and stage four are late for screening. In addition, the mortality rate is higher among patients receiving treatment in public hospitals than in private hospitals.

This is in line with the study conducted by Ho, et al (2017) found that almost 2048 (88\%) cases of death due to breast cancer in Malaysia could be avoided because 1167 (57\%) cases were due to late patients in screening. While $881(43 \%)$ cases of death due to not receiving complete treatment which indirectly indicates that there is a difference between the socioeconomic status of patients. The results of the "Malaysian Study on Cancer Survival" found 
that the risk of death from cancer based on the ratio of cases detected where the ratio rate is calculated based on Level four: Level one for breast cancer cases is 7.52 times higher (Abdullah, 2020).

In addition, the study conducted by Din, et al (2017) found that one in ten family members caring for breast cancer patients in Malaysia suffer from extreme anxiety problems caused by patient care and treatment factors. This indirectly indicates that there is a need from a psychological aspect to family members who care for and manage the needs of breast cancer patients especially husbands (if any). Researchers have found that the outcomes of effective treatment of patients can also be identified through communication issues that exist between patients and partners.

\section{The Communication Issues for Breast Cancer Patients Involving Spouses in Malaysia}

Quality of communication in marriage determines happiness in marriage as it is influences by communication tendencies, openness, and trust thus maintaining couple relationships where negative communication can lead to decreased levels of happiness in the first five years of marriage ongoing (Hou et al., 2019).

Couples who can communicate well can help the patient to cope with depression, anxiety and stress due to the disease. It can also help to ease the patient's suffering while the treatment is underway.

Since communication plays an important role in marriage, communication skills can determine happiness between patients and their respective spouses. Good communication is able to improve the quality of relationships, can control conflicts that occur in the household and in turn contribute to the mental and physical health of patients (Haris \& Kumar, 2018).

On the other hand, communication can build trust and intimacy between couples. This can increase the patient's level of trust in the partner. With this, the treatment process will be smoother because patients can be helped with a good communication system. On the other hand, the patient's condition will be worse if the partner practices negative communication to the patient such as embarrassing, criticizing, insulting or triggering an anxiety situation (Shaud \& Asad, 2018).

This article discusses 13 communication issues related to the process and outcome of treatment of breast cancer patients in Malaysia obtained through findings from previous studies. The issues found which need to be given further attention are as follows:

\section{Issue 1: Patients Vulnerable to Conflict in Marriage}

Conflict in marriage can occur because communication in marital relationships is vulnerable to conflict. This is because sharing daily lives with each other causes each partner's vulnerability to be vulnerable (Bankole, 2019).

Such a situation can be detrimental to the patient's condition as the patient suffers from depression and stress due to self -stigma. If this issue is ignored, the risk to the patient will be more dangerous, and even the treatment process will be more difficult. 


\section{Issue 2: Patients Tend to Expect Their Spouse to Communicate in Parallel to Each Other's Expectations and Expectations}

Based on theory, adults tend to expect their partner to communicate in parallel with each other's expectations and expectations (Shaud \& Asad, 2018).

If the couple do not care or chooses the path of finding a third person for self -interest, then the solution path to help the patient is not successfully found. In addition, this can cause the treatment period to be prolonged. This is due to the patient's emotions being disturbed by things other than the patient's suffering due to breast cancer disease experienced by the patient.

\section{Issue 3: Spouse Perceptions Affect Forms of Interpersonal Communication}

If spouses' perceptions are not in line with communication patterns, marital relationships will experience conflict and in turn affect forms of communication with each other (Bravo \& Martinez, 2017).

Conflicts of opinion between couples can have adverse effects during treatment. The couple should know the patient's attitude and exercise tolerance to help identify the causes and problems experienced by the patient. So, with this, the treatment process will be easier to implement and the treatment results will be more encouraging.

\section{Issue 4: Patients Experiencing Depressive Symptoms}

Patients can be prone to depression if there is a husband's behavior that can trigger conflict in the marriage. This will cause the patient to experience symptoms of depression. Husband's warmth and sincerity can help control the conflict and depression experienced by breast cancer patients (Ozguc \& Tanrıverdi, 2018).

The role of the partner is very important in helping the patient to be free from the symptoms of depression. Thus, effective communication skills between the partner and the patient can help the patient overcome the problem of depression. If the patient is successfully free of depression, the chances for the patient to recover will be faster. Even patients will feel calmer and happier during the treatment process.

\section{Issue 5: Relationship Satisfaction and Low Relationship Levels During Conflict}

Forms of communication between couples shape each other's behaviors where good relationship levels shape relationship satisfaction. While low levels of contact during conflict occur due to communication of mutual blame, hope or rejection, avoidance as well as harboring feelings (Tan et al., 2017).

Ideally, in assisting the patient during the treatment process, the couple should be more understanding of the patient's condition and more tolerant of the patient. Good communication can give the patient peace of mind even if the patient is in emotional stress or depression. Therefore, good communication can prevent patients from harboring feelings to facilitate and streamline the treatment process. 


\section{Issue 6: Self -Stigma Only Occurs in Individuals Forming Negative Attitudes in Patients}

Individuals who receive societal stigma will not necessarily also accept the problem of self stigma where self -stigma only occurs in individuals forming negative attitudes which in turn worsens their health as well as themselves (Kato, et al., 2017).

Yet if a patient has communication problems with a partner, self -stigma can occur to the patient. This is because conflicts between the partner and the patient can form negative attitudes and can adversely affect the health of the patient.

\section{Issue 7: Lowering the Level of Self -Care of Chronic Patients}

Stigma resulting from the experience or acceptance of societal stigma is likely to lower the level of self-care of chronic patients where patient self -care consists of the knowledge, skills, confidence, and behaviors of patients to manage their disease (Kato, et al., 2020).

Societal stigma can affect a patient's thinking style. The patient's tendency to believe or disbelieve any information obtained through his or her environment will affect the patient's thinking. However, if the patient has a high level of motivation and good support from a partner, the patient can be controlled even at a chronic level.

\section{Issue 8: Negative Assessments and Biased Views of Patients}

Acceptance of societal stigma becomes a barrier factor for individuals to get help or support and subsequently perform negative assessments to undergo treatment. This also influences health professionals who generally give biased views of patients such as not adhering to treatment, manipulating, and having low levels of motivation to change (Hammarlund et al., 2018).

Patients typically place a high level of trust in professionals. If professionals are biased, this can affect patients to avoid continuing to receive treatment. Even societal stigma can also influence the thoughts, attitudes, and even decisions that a patient and his or her partner will make.

\section{Issue 9: Patients Keeping the Illness a Secret}

This condition in turn causes patients who are in a chronic stage to keep their illness a secret and state that they have no invisible symptoms. This suggests that self-stigma has a relationship with self -perception is more important than societal stigma (Seo \& Song, 2020).

In addition, self-stigma is a concept in the field of mental health, yet it is becoming popular because the effects of self-stigma can increase mortality and also cause patients to neglect the health care system. The care and evaluation of patients with self-stigma requires good communication skills because there are patients who tend to be "secretive" and avoid communicating openly (Harding, 2017). The situation is becoming increasingly worrying. Based on a study conducted by Zulkipli, et al (2018), he found that the Malays are the largest use of Complimentary and Alternative Medicine-CAM, and kept it a secret from the knowledge of doctors who care for them in which breast cancer patients in stage three or more likely to use CAM based on a recommendation by family members and friends. 


\section{Issue 10: Patients Feel Afraid of Attitudes from Others}

This situation occurs because the stigma formed by individuals will cause them to feel afraid of attitudes from others such as ridicule, bias, or discrimination which in turn influences negative behaviors to overcome the resulting fear of others (Lillis et al., 2020).

Depression, low self-esteem, or loneliness will be detrimental to the patient. Therefore, couples need to play an important role and need to improve communication skills with patients in order to care for and control the patient's emotions. With this, patients can increase self-confidence and can avoid being influenced by the attitudes of others.

\section{Issue 11: Delay in Process Duration and Treatment Outcome}

Based on a study conducted by Bahri et al (2021), breast cancer patients in Malaysia use CAM due to delay in process and treatment outcome where patients post-menopausal breasts using CAM consisting of ruqyah recitations (prayers according to Islam), Chinese herbs, and supplements. This situation is explained based on a study by Kirubakaran et al (2017) who found that the majority of breast cancer patients in Malaysia consider that treatment for breast cancer requires a long period and is a painful process.

Among the reasons patients choose alternative treatment methods is due to the stigma of society. This is because the patient is easily influenced by environmental factors. Therefore, couples need to play an important role in helping patients to select and undergo the appropriate treatment process.

\section{Issue 12: The Relationship between Physician and Patient Perceptions is Low}

Nies, et al (2017) found that physicians failed to understand the perspectives and choices of breast cancer patients in the context of treatment-related decision making where the relationship between physician and patient perceptions was low. This is because patients feel they have sought a doctor's opinion to make a decision regarding their treatment.

Therefore, the involvement of the partner is necessary in helping to convey the message to the doctor, in case the doctor fails to understand the patient. If the patient and his partner have good communication with each other, then the relationship between the patient and the doctor can be improved and the treatment process will be smoother and more effective.

\section{Issue 13: Chronic Patients Through Screening}

Yeoh, et al (2018) reported that breast cancer patients in Malaysia are among the patients with the lowest life expectancy in Asia Pacific where only $49 \%$ of patients have a chance to live for five years and $43 \%$ of patients in Stage three and Stage four are late for screening as well as higher mortality rates among patients receiving treatment in public hospitals compared to private hospitals.

The societal stigma that affects patients can be a factor in why patients avoid receiving treatment. In addition, self-stigma can also be a cause of chronic patients late to undergo screening due to patients neglecting the health care system (Harding, 2017). Therefore, the role of the partner is very important in helping and reminding the patient to immediately undergo treatment. 


\section{Proposed Solutions to the Issues of Breast Cancer Patients in Malaysia}

Although there are various other issues, but researchers highlight these issues to find solutions together to help patients and partners practice appropriate communication throughout the treatment period.

Thus, the Model of Seeking Mental Health Assistance (MMBK) has combined three interrelated domains namely (1) problem identification; (2) the decision to seek assistance; and (3) selection of services agreed upon by the individual. This model was developed based on the assumption that culture includes race, ethnicity and gender in influencing all three domains (Cheng, Wang, McDermott, Kridel, \& Rislin, 2018).

In addition, awareness among women to undergo breast cancer screening has increased in October through the campaign "Pink October" launched by major international charities to raise awareness on the dangers and prevention measures of cancer (Mohamad \& Kok, 2019). The World Health Organization (WHO) has explained that the well -being of individuals is to be aware of the ability and skills to cope with the stresses of life, work optimally and contribute to the surrounding community in line with the ideas set by the Ministry of Health Malaysia $(\mathrm{MOH})$. This idea will be a factor of improvement in the mental health management system in Malaysia as a key key in the National Mental Health Strategic Action Plan 2016-2020 (Eui \& Tan, 2019).

\section{Conclusion}

Malaysia is a country that has limited resources to control cancer with a campaign to raise awareness of cancer that can lead to death. Therefore, Malaysians need more awareness campaigns through time media that are sensitive to the culture of society in Malaysia (Schliemann, et al., 2018). The current campaign is putting more focus at identifying the communication methods needed by cancer patients in Malaysia.

This can be evidenced through a study conducted by Dominic, et al (2018) that he found that programs conducted based on groups of breast cancer patients in Malaysia can reduce the level of depression, anxiety, and stress because they can interact, exchange ideas, and share information and support each other.

This indirectly indicates that the communication role of the partner of breast cancer patients is very important. Therefore, various parties should also help in terms of awareness, information, effective communication methods and others. With the help and cooperation from various parties, the issues listed can be avoided and reduced in accordance with the knowledge channeled through the media of the time. This can also help improve the health of patients and reduce cases of death due to negligence or negligence either from the patient, spouse or from a medical representative in Malaysia.

\section{Acknowledgement}

I would like to express my sincere gratitude to my supervisor, Associate Professor Dr. Jusang Bolong, for your patience, guidance, and support. I have benefited greatly from your wealth of knowledge and meticulous editing. I am extremely grateful that you took me on as a student and continued to have faith in me over the years. Thank you to my committee 
members, Associate Professor Dr. Mohd Nizam Osman and Dr. Tham Jen Sern. Your encouraging words and thoughtful, detailed feedback have been very important to me.

Most importantly, I am grateful for my husband, precious little princess and family's unconditional, unequivocal, and loving support. Last but not the least I would also like to thank all of my friends for encouraging and supporting me whenever I needed them.

Special tribute to my late sister, Allahyarhamah Nur Syamsyiah binti Che Soriah who passed away after a long battle with Triple Negative Breast Cancer (TNBC). May Allah swt shower her with HIS love and grant her the highest place in Jannah. (Alfatihah)

\section{Corresponding Author}

Saidatun Najmiah Mohd Jamil

Universiti Putra Malaysia

Email: saidatunnajmiah@yahoo.com

\section{References}

Abdullah, N. H. (2020). Kenyataan Akhbar Malaysian National Cancer Registry Report 2012 2016 (MNCRR). Ketua Pengarah Kesihatan Malaysia. Retrieved from https://nci.moh.gov.my/index.php/ms/pengumuman/722-kenyataan-akhbarmalaysia-national- cancer-registry-report-2012-2016-mncrr

Ali, R., Draman, N., Yusoff, S. S., \& Norsa'adah, B. (2020). Self-efficacy for coping with breast cancer in north-eastern state of peninsular Malaysia. Asian Pacific Journal of Cancer Prevention: APJCP, 21(10), 2971-2978.

Bahri, A. S., Mahmood, T. M., Abdul-Aziz, S. A., Makmor-Bakry, M., \& Shah, N. M. (2021). Use of adjuvant endocrine therapy among post-menopausal breast cancer patients in Malaysia. Patient Preference and Adherence, 15, 227-235.

Bankole, E. T. (2019). Communication apprehension, age, and education as predictors of marital conflict among couples in Ado-Ekiti, Ekiti State, Nigeria. Nigerian Journal of Social Psychology, 2(1), 1- 21.

Cheng, H. L., Wang, C., McDermott, R. C., Kridel, M., \& Rislin, J. L. (2018). Self-stigma, mental health literacy, and attitudes toward seeking psychological help. Journal of Counseling \& Development, 96(1), 64-74.

Din, S. H., Jaafar, N. R., Zakaria, H., Saini, S. M., Ahmad, S. N., \& Midin, M. (2017). Anxiety disorders in family caregivers of breast cancer patients receiving oncologic treatment in Malaysia. Asian Pacific Journal of Cancer Prevention: APJCP, 18(2), 465-471.

Dominic, N. A., Arasoo, V. J., Botross, N. P., Riad, A., Biding, C., \& Ramadas, A. (2018). Changes in health- related quality of life and psychosocial well-being of breast cancer survivors: Findings from a group-based intervention program in Malaysia. Asian Pacific Journal of Cancer Prevention: APJCP, 19(7), 1809-1815.

Eui, C. S., \& Tan, W. H. (2019). The mediating role of self-stigma in perceived public stigma and attitudes toward mental health help-seeking among university students in Malaysia. Thesis of Bachelor of Social Sciences Psychology, Universiti Tunku Abdul Rahman, 1-86.

Hammarlund, R., Crapanzano, K. A., Luce, L., Mulligan, L., \& Ward, K. M. (2018). Review of the 
effects of self-stigma and perceived social stigma on the treatment-seeking decisions of individuals with drug-and alcohol-use disorders. Substance Abuse and Rehabilitation, 9, 115-136.

Harding, S. (2017). Self-stigma and veteran culture. Journal of Transcultural Nursing, 28(5), 438-444.

Haris, F., \& Kumar, A. (2018). Marital satisfaction and communication skills among married couples. Indian Journal of Social Research, 59(1), 35-44.

Ho, G. F., Taib, N. A., Pritam Singh, R. K., Yip, C. H., Abdullah, M. M., \& Lim, T. O. (2017). What if all patients with breast cancer in Malaysia have access to the best available care: How many deaths are avoidable. Global Journal of Health Science, 9(8), 32-39.

Hou, Y., Jiang, F., \& Wang, X. (2019). Marital commitment, communication and marital satisfaction: An analysis based on actor-partner interdependence model. International Journal of Psychology, 54(3), 369-376.

Kato, A., Fujimaki, Y., Fujimori, S., Isogawa, A., Onishi, Y., Suzuki, R., \& Hashimoto, H. (2017). Psychological and behavioural patterns of stigma among patients with type 2 diabetes: A cross- sectional study. BMJ Open, 7(3), e013425.

Kato, A., Fujimaki, Y., Fujimori, S., Isogawa, A., Onishi, Y., Suzuki, R., \& Hashimoto, H. (2020). How self-stigma affects patient activation in persons with type 2 diabetes: A crosssectional study. BMJ Open, 10(5), e034757.

Kirubakaran, R., Jia, T. C., \& Aris, N. M. (2017). Awareness of breast cancer among surgical patients in a tertiary hospital in Malaysia. Asian Pacific Journal of Cancer Prevention: APJCP, 18(1), 115-120.

Lillis, J., Thomas, J. G., Levin, M. E., \& Wing, R. R. (2020). Self-stigma and weight loss: The impact of fear of being stigmatized. Journal of Health Psychology, 25(7), 922-930.

Mohamad, M., \& Kok, H. S. (2019). Using Google trends data to study public interest in breast cancer screening in Malaysia. Asian Pacific Journal of Cancer Prevention: APJCP, 20(5), 1427-1432.

Nies, Y. H., Islahudin, F., Chong, W. W., Abdullah, N., Ismail, F., Bustamam, R. S., \& Shah, N. M. (2017). Treatment decision-making among breast cancer patients in Malaysia. Patient Preference and Adherence, 11, 1767-1777.

Ozguc, S., \& Tanriverdi, D. (2018). Relations between depression level and conflict resolution styles, marital adjustments of patients with major depression and their spouses. Archives of Psychiatric Nursing, 32(3), 337-342.

Bravo, S. C., \& Martinez, W. A. (2017). Profiles using indicators of marital communication, communication styles, and marital satisfaction in Mexican couples. Journal of sex \& marital therapy, 43(4), 361-376.

Schliemann, D., Donnelly, M., Dahlui, M., Loh, S. Y., Ibrahim, N. S., Somasundaram, S., \& Su, T. T. (2018). The 'Be Cancer Alert Campaign': protocol to evaluate a mass media campaign to raise awareness about breast and colorectal cancer in Malaysia. BMC Cancer, 18(1), 1-10.

Seo, K., \& Song, Y. (2020). Development and validation of the self-stigma scale in people with diabetes. Nursing Open, 1-9. doi:10.1002/nop2.719

Shaud, S., \& Asad, S. (2018). Marital adjustment, convergent communication patterns, and psychological distress in women with early and late marriage. Current Psychology, 1-8. doi:10.1007/s12144- 018-9936-1

Tan, K., Jarnecke, A. M., \& South, S. C. (2017). Impulsivity, communication, and marital satisfaction in newlywed couples. Personal Relationships, 24(2), 423-439. 
Yeoh, Z. Y., Jaganathan, M., Rajaram, N., Rawat, S., Tajudeen, N. A., Rahim, N., \& Wahab, M. Y. (2018). Feasibility of patient navigation to improve breast cancer care in Malaysia. Journal of Global Oncology, 4, 1-13.

Zulkipli, A. F., Islam, T., Mohd Taib, N. A., Dahlui, M., Bhoo-Pathy, N., Al-Sadat, N., \& Hussain, S. (2018). Use of complementary and alternative medicine among newly diagnosed breast cancer patients in Malaysia: an early report from the MyBCC study. Integrative Cancer Therapies, 17(2), 312- 321. 